\title{
TEORES DE COMPOSTOS ORGÂNICOS EM CACHAÇAS PRODUZIDAS NA REGIÃO NORTE FLUMINENSE - RIO DE JANEIRO
}

\author{
Leandro Marelli de Souza* e Karla Silva Ferreira \\ Departamento de Tecnologia de Alimentos, Universidade Estadual do Norte Fluminense Darcy Ribeiro, Av. Alberto Lamego, 2000, \\ 28013-602 Campos dos Goytacazes - RJ, Brasil \\ Luís César Passoni, Alice Barreto Bevitori e Karen Vieira Melo \\ Departamento de Ciencias Químicas, Universidade Estadual do Norte Fluminense Darcy Ribeiro, Av. Alberto Lamego, 2000, \\ 28013-602 Campos dos Goytacazes - RJ, Brasil \\ Arivaldo Ribeiro Viana \\ Estação Experimental de Campos, Empresa de Pesquisa Agropecuária do Estado do Rio de Janeiro, Av. Francisco Lamego, 134, \\ 28080-000 Campos dos Goytacazes - RJ, Brasil \\ Recebido em 29/9/08; aceito em 28/5/09; publicado na web em 10/11/09

\begin{abstract}
ORGANIC COMPOUNDS CONTENTS IN CACHAÇAS PRODUCED IN THE NORTHERN RIO DE JANEIRO STATE- RJ. This work aimed to quantify some organic compounds in "cachaças" (sugar cane spirit). The ethyl alcohol was quantified by densimetry, after distillation. The acetic acid, methyl alcohol, n-propyl alcohol, n-butyl alcohol, isobutyl alcohol, isoamyl alcohol (mixture of 2-methyl-butyl and 3-methyl-butyl), ethyl acetate and acetaldehyde were determined by gas chromatography; and the furfural, 5-hydroxy-methylfurfural and acrolein by high efficiency liquid chromatography. From the 30 samples analyzed, $63.3 \%$ showed non-conformity with national legislation regarding at least one of the analyzed components.
\end{abstract}

Keywords: spirits; alcohols; beverages.

\section{INTRODUÇÃO}

A produção de cachaça representa um importante segmento do setor industrial brasileiro de bebidas, sendo a segunda bebida alcoólica mais apreciada no Brasil, perdendo apenas para a cerveja. O PIB do setor é de cerca de US\$ 500 milhões. Segundo o Ministério da Agricultura, Pecuária e Abastecimento - MAPA, são produzidos, aproximadamente, 1,4 bilhões de litros de cachaça por ano no Brasil. ${ }^{1}$ Em 2008 foram exportados 11,2 milhões de litros, gerando uma arrecadação de, aproximadamente, 16,4 milhões de dólares. ${ }^{2}$

Existem mais de 4 mil marcas registradas no Ministério da Agricultura, Pecuária e Abastecimento e mais de 30 mil produtores em todo país, gerando aproximadamente 400 mil empregos diretos e indiretos. ${ }^{1}$ Dentre estas empresas, destacam-se as micro, pequenas e médias empresas. ${ }^{3}$

Durante a fermentação alcoólica ocorre formação de dois produtos principais: álcool etílico e dióxido de carbono. Além desses, há, normalmente a formação de pequenas quantidades de outros componentes, os quais recebem a denominação de produtos secundários da fermentação alcoólica, tais como ácidos carboxílicos, ésteres, aldeídos e álcoois superiores. ${ }^{4}$

A cachaça é regulamentada pelo MAPA, por meio da Instrução Normativa $\mathrm{N}^{\circ} 13 .{ }^{5}$ Tal Normativa estabelece a composição química, os requisitos de qualidade e a concentração máxima permitida de contaminantes, como cobre e carbamato de etila. Os padrões de identidade e qualidade, estabelecidos pela legislação, com seus respectivos limites têm a finalidade de padronizar a cachaça e proteger a saúde do consumidor. Essa padronização é essencial para que a bebida atenda aos padrões internacionais de qualidade e seja aceita pelo mercado externo, proporcionando condições de abertura e manutenção do mercado de exportação, ${ }^{6}$ além de proporcionar aceitação, no mercado interno, pelas classes de maior poder aquisitivo, as quais exigem bebidas com maior controle de qualidade.

\footnotetext{
*e-mail: marelliuenf@ hotmail.com
}

A região Norte do Estado do Rio de Janeiro destaca-se pelo plantio de cana-de-açúcar. Além da produção de açúcar e álcool por grandes usinas, há vários produtores de cachaça. Grande parte deles são cooperados da Cooperativa dos Produtores de Cachaça e Derivados da Cana-de-Açúcar do Norte Fluminense (COOPCANF). Este estudo objetiva quantificar alguns compostos orgânicos em cachaças produzidas por estes cooperados e avaliar sua conformidade com os padrões de identidade e qualidade estabelecidos pela legislação vigente.

\section{PARTE EXPERIMENTAL}

\section{Amostras}

Foram coletadas 30 amostras de volume variando entre 600 a 1000 $\mathrm{mL}$ de cachaça de dezesseis associados da Cooperativa dos Produtores de Cachaça e Derivados da Cana-de-Açúcar do Norte Fluminense (COOPCANF) do Estado do Rio de Janeiro que estavam produtivos ou que tinham produtos no mercado, no segundo semestre de 2006 e primeiro semestre de 2007. As amostras foram adquiridas por meio de compra no comércio de Campos dos Goytacazes - RJ ou diretamente nos alambiques. O número de amostras de cada marca variou de 1 a 6 , dependendo da existência de cachaças com diferentes características na época da pesquisa. Na Tabela 1 estão descritas as características de cada amostra.

\section{Reagentes e padrões}

Os padrões metanol, etanol, 1-propanol, 1-butanol, iso-butanol, iso-amílico, acetato de etila, acetaldeído e ácido acético foram de grau cromatográfico (Fluka e Sigma) e acroleína (Fluka), furfural e 5-hidroximetilfurfural (Chem service).

O reagente 2,4-dinidrofenilidrazina (Chem Service) foi purificado por três sucessivas recristalizações em etanol. Os demais reagentes utilizados foram de grau analítico (Merck e Sigma). 
Tabela 1. Relação das amostras de cachaça analisadas, respectivas indústrias e o critério de diferenciação

\begin{tabular}{|c|c|c|}
\hline Indústria & Amostras & Critério de diferenciação \\
\hline \multirow[t]{6}{*}{ marca 1} & 1 & Prata, armazenada por 6 meses em reservatório de aço carbono. \\
\hline & 2 & Prata, armazenada por 1 ano em reservatório de aço carbono. \\
\hline & 3 & Prata, armazenada por 2 anos em reservatório de aço carbono. \\
\hline & 4 & Prata sem identificação quanto ao ano de produção. \\
\hline & 5 & Armazenada por 2 anos em barril de cerejeira. \\
\hline & 6 & Armazenada por 2 anos em barril de carvalho. \\
\hline \multirow[t]{3}{*}{ marca 2} & 7 & Armazenada por 1 ano em barril de carvalho e produzida em 2006. \\
\hline & 8 & Armazenada por 2 anos em barril de carvalho e produzida em 2005 . \\
\hline & 9 & Armazenada por 2 anos em barril de carvalho e produzida em 2001. \\
\hline \multirow[t]{5}{*}{ marca 3 (Orgânica) } & 10 & Armazenada por 1 semana em barril de balsamo. \\
\hline & 11 & Blend (safra 2006 com 2007) e armazenada em barril de bálsamo. \\
\hline & 12 & Armazenada por 4 anos em barril de carvalho. \\
\hline & 13 & Armazenada em barril de carvalho (tempo não especificado). \\
\hline & 14 & Armazenada por 2 anos em barril de carvalho. \\
\hline \multirow[t]{2}{*}{ marca 4} & 15 & Armazenada por 4 anos em barril de carvalho. \\
\hline & 16 & Armazenada por 5 anos em barril de carvalho. \\
\hline \multirow[t]{3}{*}{ marca 5} & 17 & Prata produzida em 2007. \\
\hline & 18 & Safra 2006, armazenada por 1 ano em barril (madeira desconhecida). \\
\hline & 19 & Envelhecida (madeira e tempo desconhecidos). \\
\hline marca 6 & 20 & Prata produzida no ano de 2006. \\
\hline marca 7 & 21 & Prata produzida no ano de 2006. \\
\hline marca 8 & 22 & Armazenada em barris de bálsamo e carvalho por tempo desconhecido. \\
\hline marca 9 & 23 & Prata produzida no ano de 2006. \\
\hline marca 10 & 24 & Prata sem identificação quanto ao ano de produção. \\
\hline marca 11 & 25 & Prata sem identificação quanto ao ano de produção. \\
\hline marca 12 & 26 & Prata sem identificação quanto ao ano de produção. \\
\hline marca 13 & 27 & Prata sem identificação quanto ao ano de produção. \\
\hline marca 14 & 28 & Envelhecida (madeira e tempo desconhecidos). \\
\hline marca 15 & 29 & Prata produzida no ano de 2007. \\
\hline marca 16 & 30 & Prata produzida no ano de 2002. \\
\hline
\end{tabular}

\section{Metodologias analíticas}

A quantificação do teor alcoólico real foi realizada por densimetria após destilação, de acordo com o Manual de Métodos de Análises de Bebidas e Vinagres do Ministério da Agricultura. ${ }^{7}$

O ácido acético, metanol, 1-propanol, 1-butanol, iso-butanol, iso-amílico (3-metil-1-butanol + 2-metil-1-butanol), acetato de etila e acetaldeído foram determinados diretamente, sem concentração prévia da amostra, por cromatografia gasosa $(G C=$ Gas Chromatography), usando cromatógrafo a gás Shimadzu, modelo GC-17A, equipado com um detector de ionização em chama $(F I D=$ Flame ionization detection $)$ e separados em uma coluna capilar polar LM-100, série CB (35 m x 0,25 mm x 0,25 $\mu \mathrm{m})$. As temperaturas do detector e do injetor foram fixadas em $250{ }^{\circ} \mathrm{C}$ e o modo de injeção com divisão de fluxo (split) de 1:25 com um volume de injeção de $1,00 \mu \mathrm{L}$ da amostra (cachaça). Todas as análises, tanto das curvas analíticas, quanto das amostras, foram feitas em duplicata e quando apresentavam discrepância, em triplicata. O fluxo do gás de arraste na coluna $\left(\mathrm{H}_{2}\right)$ foi de 1,0 $\mathrm{mL} / \mathrm{min}$. A temperatura da coluna seguiu uma programação. $\mathrm{O}$ programa de temperatura utilizado na coluna foi: $35^{\circ} \mathrm{C}$ (isoterma de $7 \mathrm{~min}$ ), $7^{\circ} \mathrm{C} / \mathrm{min}$ até $90{ }^{\circ} \mathrm{C}$ (isoterma de $5 \mathrm{~min}$ ), e $15^{\circ} \mathrm{C} / \mathrm{mim}$ até $120{ }^{\circ} \mathrm{C}(1,0 \mathrm{~min})$.

As curvas analíticas foram preparadas contendo cinco pontos, nas seguintes faixas de concentração, em mg $100 \mathrm{~mL}^{-1}$ de álcool anidro : acetaldeído (7,5 a 37,5), acetato de etila (50 a 250), metanol (5 a 25), 1-propanol (30 a 150), iso-butanol (30 a 150), 1-butanol (0,75 a 3,75), iso-amílico (30 a 150) e ácido acético (37,5 a 187,5) em meio hidroalcoólico (etanol $40 \% \mathrm{v} / \mathrm{v}$ ), procurando-se reproduzir as condições da matriz analisada. Utilizou-se a regressão linear, plotando-se a relação área dos picos dos padrões/área do padrão interno versus concentração. Os coeficientes de correlação foram sempre bem próximos à unidade. O 4-metil-2-pentanol, grau UV/ HPLC foi o padrão interno usado.

O cromatograma dos padrões do acetaldeído, acetato de etila, ácido acético, os alcoóis (metanol, etanol, 2-butanol, 1-propanol, 
iso-butanol, 1-butanol e iso-amílico) e o padrão interno 4-metil-2pentanol obtidos por cromatografia gasosa $(G C=$ Gas Chromatography), equipado com um detector de ionização em chama $(F I D=$ Flame ionization detection) em uma coluna capilar polar LM-100 com a identificação dos picos encontram-se na Figura 1.

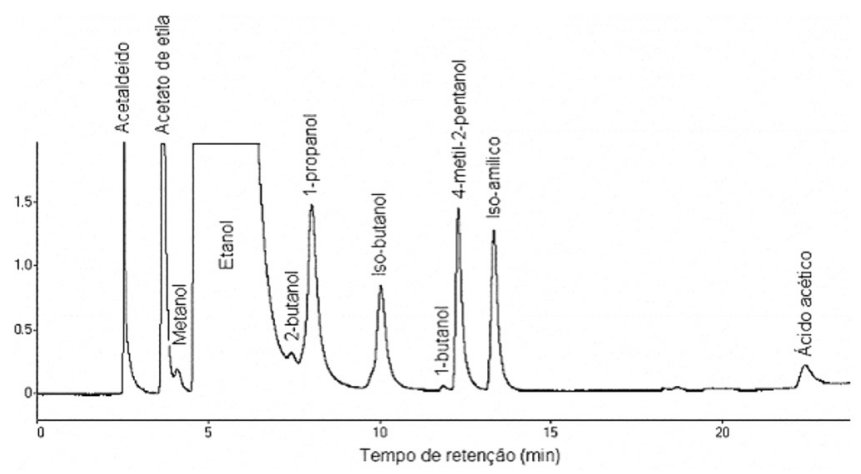

Figura 1. Cromatograma dos padrões obtido por GC-FID em coluna polar LM-100

Os compostos acroleína, furfural e 5-hidroximetilfurfural foram quantificados por Cromatografia Líquida de Alta Eficiência (HPLC = High Performance Liquid Chromatography) em cromatógrafo Shimadzu (modelo LC-10AD), com injetor Shimadzu (loop de 20 $\mu \mathrm{L}$ ), detector espectrofotométrico UV-Visível, (modelo SPD-M10A) e coluna Supelcosil ${ }^{\mathrm{TM}} \mathrm{LC}-18(5 \mu)$, com $250 \mathrm{~mm}$ de comprimento e 4,6 mm de diâmetro interno. Todas as amostras e fase móvel foram degaseificadas em lavadora ultrassônica, marca Ultra Sonic Cleaner. Aproximadamente, $1,0 \mathrm{~mL}$ de cada amostra, no momento da injeção, foi filtrado em filtro PTFE para filtrações de solventes orgânicos, com $0,45 \mu$ de diâmetro de poro, marca Millipore. Todas as injeções, tanto das curvas analíticas, quanto das amostras, foram feitas em duplicata, e quando apresentavam discrepância, em triplicata, com um volume de injeção de $20 \mu \mathrm{L}$.

A fase móvel usada foi metanol:água. O metanol de grau UV/ HPLC e a água utilizada purificada pelo sistema Milli-Q (Millipore Bedford, USA). O gradiente de eluição empregado foi metanol:água $(65: 35 \mathrm{v} / \mathrm{v})$ por $5 \mathrm{~min}$, metanol:água $(85: 15 \mathrm{v} / \mathrm{v}) \mathrm{em} 10 \mathrm{~min} \mathrm{e}$

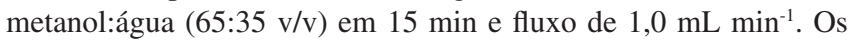
derivados foram quantificados a $365 \mathrm{~nm}$ e o tempo de corrida foi de $15 \mathrm{~min}$.
Os derivados carbonílicos da 2,4-dinidrofenilidrazina $(2,4$ DNPH) foram obtidos conforme descrito por Saczk e colaboradores ${ }^{8}$ com modificações. Para cada um dos padrões pesaram-se 0,40 g de 2,4 DNPH, posteriormente, dissolvidos em ácido sulfúrico concentrado $(2,0 \mathrm{~mL})$ e água destilada $(3,0 \mathrm{~mL})$. Nestas soluções foram adicionados $0,10 \mathrm{~g}$ de cada padrão, dissolvido em etanol (15,0 mL). Os padrões 5-hidroximetilfurfural e acroleína tinham pureza de $99,5 \%$ e furfural, $98,9 \%$. Este material foi centrifugado a $1800 \mathrm{rpm}$ por $5 \mathrm{~min}$ e o sobrenadante foi descartado. O precipitado foi lavado com $5,0 \mathrm{~mL}$ de etanol absoluto e centrifugado a $1800 \mathrm{rpm}$ durante $5 \mathrm{~min}$. Esse processo foi repetido por duas vezes. Após a centrifugação, o precipitado foi deixado durante 4 dias em temperatura de $30{ }^{\circ} \mathrm{C}$, dentro de um béquer coberto com filme plástico com pequenos furos, para a evaporação do etanol. Este material foi diluído em etanol-água (40:60 v/v) para o preparo da solução estoque de acroleína-DNPH, furfural-DNPH e 5-hidroximetilfurfural-DNPH com concentração de $1000 \mathrm{mg} \mathrm{L}^{-1}$. As curvas analíticas foram construídas usando-se cinco pontos com faixa de concentração de 5 a $25 \mathrm{mg} \mathrm{L}^{-1}$. Para a análises destes compostos nas cachaças, 4,0 mL de cada amostra foi colocada em tubo de ensaio de $50 \mathrm{~mL}$, adicionando-se $1,00 \mathrm{~mL}$ de solução 0,4\% de 2,4-DNPH diluído em acetonitrila e 50,0 $\mu \mathrm{L}$ de $\mathrm{HClO}_{4} 1,0$ mol L ${ }^{-1}$ A solução resultante foi agitada e mantida à temperatura ambiente por 40 min até a injeção no cromatógrafo.

\section{RESULTADOS E DISCUSSÃO}

Na Tabela 2 são apresentados os valores máximos, mínimos, médios e desvio padrão dos componentes detectados nas amostras de cachaça e na Tabela 3 o número e porcentagem de amostras que não atendem aos parâmetros de identidade e qualidade segundo a Instrução Normativa $\mathrm{N}^{\circ} 13 .{ }^{5}$ A Figura 2 ilustra o grau alcoólico das diferentes amostras analisadas.

Os estudos demonstraram a existência de nove amostras, $30 \%$, com teor alcoólico abaixo do aceitável pela legislação e apenas uma amostra apresentava o teor real de etanol encontrado idêntico ao informado no rótulo (marca 12). Discrepância entre o teor real de etanol e o informado no rótulo das cachaças, na maioria das vezes, ocorre por negligência do produtor. A principal delas é a temperatura do destilado no momento da medida do grau alcoólico, que deve ser de $20{ }^{\circ} \mathrm{C}$. Caso não seja possível ajustar a temperatura do destilado, o produtor deve efetuar a correção da temperatura no momento da leitura usando tabelas de conversão para $20^{\circ} \mathrm{C} .{ }^{9}$

Tabela 2. Limites máximos e mínimos, composição físico-química, média e desvio padrão dos componentes analisados

\begin{tabular}{|c|c|c|c|c|c|c|}
\hline \multirow{2}{*}{ Componentes } & \multirow{2}{*}{ Unidades } & \multicolumn{2}{|c|}{ Limites* } & \multirow{2}{*}{$\begin{array}{l}\text { Valor } \\
\text { máximo }\end{array}$} & \multirow{2}{*}{$\begin{array}{l}\text { Valor } \\
\text { mínimo }^{1}\end{array}$} & \multirow{2}{*}{$\begin{array}{c}\text { Valor médio } \pm \text { desvio } \\
\text { padrão }\end{array}$} \\
\hline & & Mínimo & Máximo & & & \\
\hline Grau alcoólico & $\begin{array}{c}\% \text { em volume de álcool } \\
\text { etílico a } 20^{\circ} \mathrm{C}\end{array}$ & 38 & 48 & 46,0 & 32,0 & $38,8 \pm 2,7$ \\
\hline Furfural+ hidroximetilfurfural & mg $100 \mathrm{~mL}^{-1}$ álcool anidro & --- & 5,0 & 9,5 & 1,1 & $4,2 \pm 2,0$ \\
\hline Acidez volátil, em ácido acético & mg $100 \mathrm{~mL}^{-1}$ álcool anidro & --- & 150 & 186,3 & N.D & $98,8 \pm 41,9$ \\
\hline 1-Butanol & mg $100 \mathrm{~mL}^{-1}$ álcool anidro & --- & 3,0 & 3,2 & N.D & $1,3 \pm 0,9$ \\
\hline Álcool metílico (Metanol) & mg $100 \mathrm{~mL}^{-1}$ álcool anidro & --- & 20 & 28,9 & N.D & $5,7 \pm 4,7$ \\
\hline Alcoóis superiores** & mg $100 \mathrm{~mL}^{-1}$ álcool anidro & --- & 360 & 554,5 & 120,8 & $236,1 \pm 82,7$ \\
\hline Acroleína & mg $100 \mathrm{~mL}^{-1}$ álcool anidro & --- & 5 & 7,9 & N.D & $0,5 \pm 1,5$ \\
\hline Aldeídos, em acetaldeído & mg $100 \mathrm{~mL}^{-1}$ álcool anidro & --- & 30 & 22,2 & 7,4 & $14,9 \pm 3,4$ \\
\hline Ésteres, em acetato de etila & mg $100 \mathrm{~mL}^{-1}$ álcool anidro & --- & 200 & 170,8 & 27,4 & $58,5 \pm 33,5$ \\
\hline
\end{tabular}

${ }^{1}$ Média das duplicatas; (N.D) Não detectado. *Limites estabelecidos pela Instrução Normativa $\mathrm{N}^{\circ} 13 .{ }^{5} * *$ Alcoóis superiores $=$ soma dos alcoóis iso-butílico (2-metil-propanol), iso-amílicos (2-metil-1-butanol e 3-metil-1-butanol) e n-propílico (1-propanol). 
Tabela 3. Número de amostras de cachaça das 30 analisadas que não atendem aos parâmetros de identidade e qualidade propostos pela Instrução Normativa $\mathrm{N}^{\circ} 13^{5}$

\begin{tabular}{lcc}
\hline Componentes & $\begin{array}{c}\text { Número de amostras } \\
\text { irregulares* }\end{array}$ & Porcentagem \\
\hline Grau alcoólico real & 9 & $30,0 \%$ \\
Furfural+hidroximetilfurfural & 9 & $30,0 \%$ \\
Ácido acético & 4 & $13,3 \%$ \\
1-Butanol & 3 & $10,0 \%$ \\
Metanol & 1 & $3,3 \%$ \\
Álcoois superiores** & 1 & $3,3 \%$ \\
Acroleína & 1 & $3,3 \%$ \\
Acetaldeído & - & $0,0 \%$ \\
Acetato de etila & - & $0,0 \%$ \\
\hline
\end{tabular}

*Amostras irregulares conforme Instrução Normativa $\mathrm{N}^{\circ} 13 .{ }^{5} * *$ Álcoois superiores = soma dos álcoois iso-butílico (2-metil-propanol), iso-amílicos (2-metil-1-butanol e 3-metil-1-butanol) e n-propílico (1-propanol).

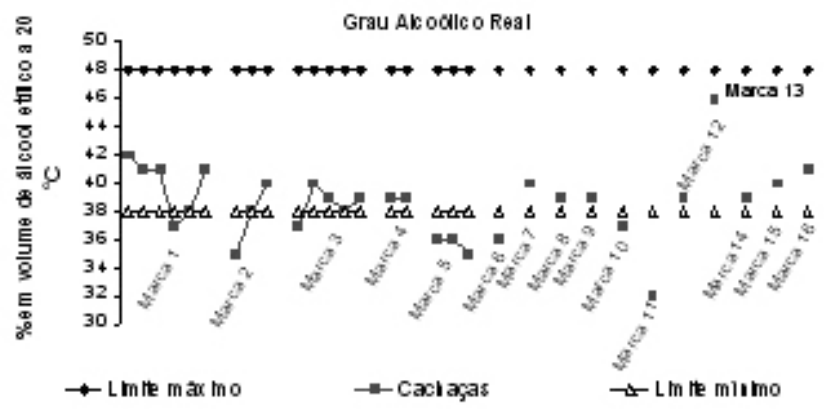

Figura 2. Valores de grau alcoólico das diferentes amostras analisadas e limite mínimo e máximo para um destilado ser considerado cachaça, conforme instrução Normativa $n^{\circ} 13^{5}$

Em um estudo investigando os parâmetros de qualidade em aguardentes de cana produzidas no Estado da Paraíba, os autores descrevem uma não conformidade em $20 \%$ das amostras estudadas, referente à graduação alcoólica. ${ }^{10}$ Outros estudos indicaram valores próximos a $10 \% .^{6-11}$

A soma dos teores de furfural e 5-hidroximetilfurfural (5-HMF) variaram de 1,1 a $9,5 \mathrm{mg} 100 \mathrm{~mL}^{-1}$ álcool etílico anidro, sendo que nove amostras (30\%) continham teores acima do máximo permitido. Estudos detectaram teores máximos de $8,8 \mathrm{mg} 100 \mathrm{~mL}^{-1}$ álcool etílico anidro para o composto furfural em amostras de cachaça artesanal de cana não queimada. ${ }^{12}$ Análises de 31 amostras de cachaça pertencentes ao acervo do Laboratório de Biotecnologia (Labiotec/Detal/ UFC) continham teores máximos, em $\mathrm{m} \mathrm{L}^{-1}$ de cachaça, próximos a 19,05 para o 5-HMF e 9,6 para furural..$^{13}$

As presenças de furfural e 5-HMF em bebidas podem estar relacionadas à queima do palhiço da cana-de-açúcar, à presença de açúcares residuais e de bagacilhos. A temperatura elevada associada ao baixo $\mathrm{pH}$ do mosto acarreta desidratação dos açúcares e hidrólise de polissacarídeos dos bagacilhos (celulose, hemicelulose, pectina e outros) formando furfural e 5-HMF. ${ }^{14}$ As pentoses formam furfural como principal produto de degradação, enquanto as hexoses formam 5-HMF (Figura 3). Outros fatores, como o envelhecimento da bebida sob condições irregulares e a adição de caramelo, também, podem contribuir para o aumento no teor destes componentes. ${ }^{13-15}$<smiles>O=Cc1ccco1</smiles><smiles>O=Cc1ccc(CO)o1</smiles>

Figura 3. Estrutura química do furfural e do 5-hidroximetilfurfural

O cromatograma da Figura 4 ilustra os picos correspondentes para acetaldeído, acetato de etila, ácido acético, os álcoois (metanol, etanol, 1-propanol, iso-butanol, 1-butanol, iso-amílico) e o padrão interno 4-metil-2-pentanol identificados em amostras de cachaças.

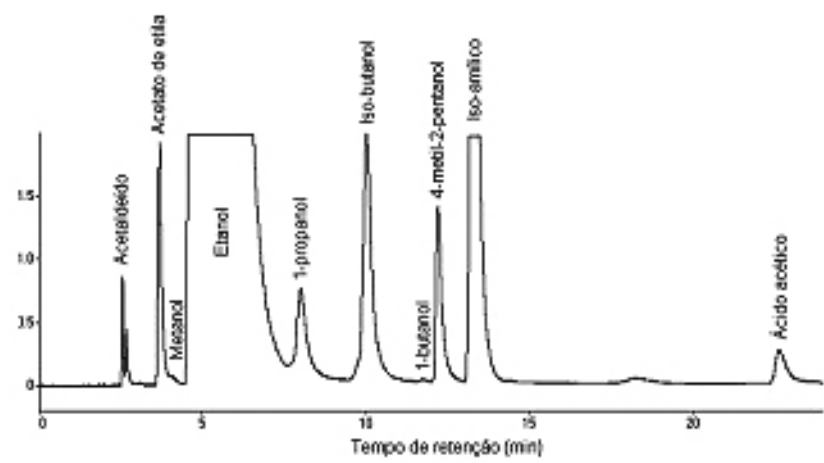

Figura 4. Cromatograma típico de amostras de cachaça obtido por GC-FID em coluna polar LM-100. As condições cromatográficas estão descritas em materiais e métodos

A Instrução Normativa $\mathrm{N}^{\circ} 13^{5}$ estabelece uma concentração máxima de acidez volátil, em ácido acético de $150 \mathrm{mg} 100 \mathrm{~mL}^{-1}$ álcool etílico anidro. Neste estudo, quatro amostras apresentaram teores de ácido acético acima do permitido, representando 13,3\% das amostras analisadas. O teor máximo encontrado em mg 100 $\mathrm{mL}^{-1}$ álcool etílico anidro foi de 186,3 na amostra 15 (marca 4). Outras amostras em excesso são: amostra $16(160,8), 24(165,2)$ e $28(165,2)$. Estudos usando amostras de cachaças da região Noroeste do Rio Grande do Sul apresentam dados de acidez volátil de algumas amostras acima do máximo estabelecido por lei. ${ }^{16}$ Este estudo descreve valores máximos, em mg $100 \mathrm{~mL}^{-1}$ álcool etílico anidro, de 185,8 para cachaças produzidas na microrregião de Cruz Alta e 180,0 para as amostras produzidas na microrregião de Santa Rosa. Outras pesquisas utilizando 94 cachaças comerciais ${ }^{6}$ e investigações de compostos secundários em 45 diferentes cachaças comerciais produzidas no Estado de Minas Gerais, ${ }^{17}$ também, apresentam resultados com amostras (8,5 e 6,7\%, respectivamente) excedendo o teor máximo permitido pela legislação vigente.

A acidez em cachaças pode ser devido à contaminação da canade-açúcar ou do próprio mosto fermentado por bactérias acéticas (acetobacter), tanto na estocagem da cana-de-açúcar quanto do próprio caldo. ${ }^{4} \mathrm{~A}$ acidez volátil, também, aumenta com o aumento do tempo de armazenamento da cachaça em barris de madeira. ${ }^{18}$ Estes autores ${ }^{18}$ verificaram aumento na acidez volátil de $14,3 \mathrm{mg} 100 \mathrm{~mL}^{-1}$ álcool etílico anidro em destilados após 36 meses de armazenamento em barris de carvalho com capacidade para 250 L. Já outros trabalhos mostraram que o descarte das frações dos destilados "cabeça" e "cauda", especialmente da última, reduz a acidez das aguardentes. ${ }^{19,20}$

O 1-butanol e metanol são contaminantes de cachaça e, consequentemente, não devem ser encontrados ou somente detectados em valores baixos. A instrução Normativa $\mathrm{N}^{\circ} 13$ permite o valor máximo do 1-butanol de 3,0 mg $100 \mathrm{~mL}^{-1}$ álcool etílico anidro. ${ }^{5}$ Três amostras apresentaram teores acima do permitido, em mg $100 \mathrm{~mL}^{-1}$ de álcool 
etílico anidro, mas muito próximos do limite máximo. Essas amostras foram: $9(3,1), 15(3,2)$ e $21(3,1)$. Em 16,7\% das amostras o teor de 1-butanol não foi detectado. O principal fator para formação de 1-butanol em cachaças é a contaminação por bactérias acetobutílicas durante o processo de fermentação. Esta contaminação pode ser reduzida não deixando a cana-de-açúcar próxima a estábulos e locais de ordenha. ${ }^{21}$

O teor de metanol foi superior ao estabelecido pela legislação apenas na amostra 24 (marca 10) com 28,9 mg $100 \mathrm{~mL}^{-1}$ álcool etílico anidro. Nas demais amostras, os teores detectados foram abaixo de

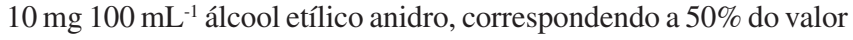
máximo permitido pela Instrução Normativa $N^{\circ} 13 .{ }^{5}$ Trabalhos atuais não têm detectado teores de metanol acima do máximo permitido pela legislação. ${ }^{12,16,18,22}$ Dentre estes, alguns resultados são muito próximos ao encontrado no presente estudo. ${ }^{22}$

O metanol presente na cachaça origina-se do metabolismo secundário das leveduras. Os fatores que propiciam sua formação são a queima da cana-de-açúcar no momento da colheita, o acréscimo de frutas ao caldo-de-cana durante a fermentação e limpeza inadequada do alambique, deixando resíduos de bagacilhos nas paredes internas do mesmo. ${ }^{21}$ Os bagacilhos são ricos em substâncias pécticas, polímeros de ácido galacturônico com grau variável de metoxilação. ${ }^{23}$ A atuação de enzimas pécticas das leveduras libera o metanol. ${ }^{24}$ No organismo, o metanol é oxidado a ácido fórmico e, posteriormente, a $\mathrm{CO}_{2}$, provocando acidose (diminuição do $\mathrm{pH}$ sanguíneo) e afetando o sistema respiratório, podendo levar ao coma e até mesmo à morte. ${ }^{23}$ O teor de metanol em cachaças, também, pode estar relacionado com o material utilizado na fabricação do alambique, sendo superior em aguardentes destiladas em alambiques de cobre, quando comparados com alambiques de aço inox. ${ }^{25}$

O limite máximo para os álcoois superiores foi elevado de $300^{26}$ para $360 \mathrm{mg} 100 \mathrm{~mL}^{-1}$ álcool etílico anidro, ${ }^{5}$ permitindo o comércio de uma bebida mais "encorpada". Os valores dos alcoóis superiores foram obtidos pela soma dos alcoóis iso-butílico (2-metil propanol), iso-amílicos (2-metil -1-butanol e 3-metil-1-butanol) e propílico (1- propanol). Apenas a marca 10 (amostra 24) excedeu ao limite máximo permitido pela legislação atual, sendo que em todas as demais cachaças os teores deste composto apresentavam-se dentro dos limites estipulados pela legislação. Houve uma grande variação no teor de alcoóis superiores (em mg $100 \mathrm{~mL}^{-1}$ álcool etílico anidro), com mínima de 120,8 e máxima de 554,5 (Tabela 2). Estudos realizados por Miranda e colaboradores ${ }^{6}$ detectaram 4 amostras com os teores destes alcoóis fora do limite estabelecido pela legislação em um universo de 94 amostras. Porém, Barcelos e colaboradores ${ }^{27}$ não detectaram amostras irregulares, mas observaram diferença significativa entre os teores detectados nas amostras do Sul de Minas (média de 176,6 mg $100 \mathrm{~mL}^{-1}$ álcool etílico anidro) quando comparados com as produzidas no Vale do Jequitinhonha (média de 235,1 mg $100 \mathrm{~mL}^{-1}$ álcool etílico anidro). Amostras coletadas na Zona da Mata apresentaram valores intermediários (média de 221,9 mg $100 \mathrm{~mL}^{-1}$ álcool etílico anidro).

A formação de alcoóis superiores é maior quando o fermento apresenta atividade fraca, ocasionando demora no processo fermentativo. ${ }^{28}$ As condições do meio de fermentação, a temperatura e o teor alcoólico final do vinho são fatores que interferem na concentração de alcoóis superiores em destilados.$^{27}$ Outras variáveis, como a concentração de aminoácidos e $\mathrm{pH}$ do mosto, o intervalo de tempo entre a fermentação e a destilação e o tempo prolongado de armazenamento da cana-de-açúcar, também, interferem no teor de alcoóis superiores. ${ }^{29}$

A acroleína é extremamente tóxica por todas as vias de administração e tem mostrado características mutagênicas, além de provocar irritação no trato respiratório de animais e humanos. ${ }^{15}$ Neste estudo, apenas a amostra 22 (com 7,9 mg $100 \mathrm{~mL}^{-1}$ álcool etílico anidro) excedeu o limite permitido pela legislação (Tabela 2). Nascimento e colaboradores ${ }^{30}$ descreveram em seus resultados um teor máximo de 0,7 mg $100 \mathrm{~mL}^{-1}$ álcool etílico anidro. A produção de acroleína pela transformação de 3-hidroxipropanal é comum em cidras e provoca uma alteração indesejada, responsável pelo aroma de pimenta nas bebidas. Nos vinhos, este metabolismo é associado à presença das bactérias termofermentativas: Bacillus amaracrylus e Lactobacillus colinoides. ${ }^{15}$

Os teores dos compostos acetaldeído e acetato de etila não excederam o valor máximo permitido pela legislação ${ }^{5}$ em nenhuma das amostras. Estes resultados condizem com os estudos realizados com amostras de cachaças produzidas na Região Noroeste do Rio Grande do Sul ${ }^{16}$ e amostras coletadas em diferentes unidades produtoras da região de Araras, Estado de São Paulo, provenientes de destilação em colunas de fluxo contínuo. ${ }^{18}$ Entretanto, em 94 amostras de cachaças produzidas em diferentes regiões brasileiras foram detectadas 6 amostras com teores de acetato de etila acima do limite permitido e 16 com excesso de acetaldeído. ${ }^{6}$ Altos teores de aldeídos nas cachaças podem ser indicação de oxidação espontânea ou devido à atividade de bactérias contaminantes, ${ }^{28}$ podendo influenciar negativamente o sabor da aguardente por ocasionar aumento do sabor pungente das bebidas alcoólicas. ${ }^{31}$

Estudos indicam o aumento significativo nos teores de acetaldeído e acetato de etila após 36 meses de envelhecimento em barris de madeira. ${ }^{18}$ Segundo estes autores, recipientes de madeira transferem compostos existentes em sua estrutura à bebida e teores mais elevados de acetaldeído e acetato de etila são indicativos de envelhecimento das cachaças. Estes dados condizem com os resultados obtidos neste estudo, quando foi possível comparar amostras com características diferentes, pertencentes a uma mesma marca; as armazenadas em barril de madeira por períodos mais longos apresentavam teores destes compostos superiores aos de amostras com menor tempo de armazenamento.

Um outro fator importante na composição química das cachaças é o material utilizado para fabricação do alambique. Nascimento e colaboradores,${ }^{25}$ ao estudarem a influência do material do alambique, detectaram maiores teores de acetaldeído nas cachaças destiladas em alambiques de cobre. As aguardentes destiladas nesse tipo de alambique apresentaram teores médios de aldeídos, aproximadamente, 50\% superiores às destiladas em alambique de aço inox.

\section{CONCLUSÕES}

Em relação aos atuais padrões de identidade e qualidade para a cachaça, estabelecidos na legislação brasileira, apenas 36,7\% das amostras estão em conformidade com a legislação ${ }^{5}$ em todos os itens analisados. O grau alcoólico real e a soma dos compostos 5-hidroximetilfurfural e furfural foram os parâmetros com maiores índices de irregularidades apresentados pelas amostras, em seguida, encontra-se o ácido acético. Os alcoóis superiores (soma dos alcoóis iso-butílico, iso-amílicos e propílico), o ácido acético e o acetato de etila foram os componentes que apresentaram os maiores desvios padrão, refletindo as dificuldades enfrentadas pelos produtores em garantir a qualidade e a padronização da bebida em todas as etapas da produção. O alto índice de amostras $(63,3 \%)$ que se revelaram em não conformidade com a legislação, ${ }^{5}$ em pelo menos um dos componentes analisados, compromete as exportações e dificulta o crescimento do mercado interno da cachaça. A cachaça pertencente à marca dez destacou-se em relação às demais amostras, por obter o maior índice de irregularidade, com teores de ácido acético, metanol e álcoois superiores acima do limite máximo permitido e, ainda, teor alcoólico real abaixo do permitido.

\section{AGRADECIMENTOS}

À FAPERJ pelo Auxílio Pesquisa para a execução do projeto e bolsa do doutorando, e aos produtores pelas amostras de cachaça cedidas. 


\section{REFERÊNCIAS}

1. http:www.agricultura.gov.br, acessada em Julho 2008.

2. http://aliceweb.desenvolvimento.gov.br, acessada em Julho 2008.

3. http://www.abrabe.org.br/cachaca.php, acessada em Julho 2008.

4. Cardoso, M. G., ed.; Produção de aguardente de cana, $2^{\mathrm{a}}$ ed., Ed. UFLA: Lavras, 2006, cap. 5.

5. BRASIL. Ministério da Agricultura, Pecuária e Abastecimento; Instrução Normativa $\mathrm{N}^{\circ} 13$, de 29 de junho de 2005, Diário Oficial da União 30/6/2005.

6. Miranda, M. B.; Martins, N. G. S.; Belluco, A. E. S.; Horii, J.; Alcarde, A. R.; Cienc. Tecnol. Aliment. 2007, 27, 897.

7. BRASIL. Metodologias de análises de bebidas e vinagres. Disponível em http://www.agricultura.gov.br, atualizado em 14/07/2005.

8. Saczk, A. A.; Okumura, L. L.; Oliveira, M. F.; Zanoni, M. V. B.; Stradiotto, N. R.; Anal. Bioanal. Chem. 2005, 381, 1619.

9. Dias, S. M. B. C. Em ref. 4.

10. Lima, A. K. S.; Nóbrega, I. C. C.; B. CEPPA 2004, 22, 85.

11. Vilela, F. J.; Cardoso, M. G.; Masson, J.; Anjos, J. P.; Cienc. Agrotec. 2007, 31, 1089.

12. Masson, J.; Cardoso, M. G.; Vilela, F. J.; Pimentel, F. A.; Morais, A. R.; Anjos, J. P.; Cienc. Agrotec. 2007, 31, 1805.

13. Aquino, F. W. B.; Nascimento, R. F.; Rodrigues, S.; Casemiro, A. R. S.; Cienc. Tecnol. Aliment. 2006, 26, 145.

14. Maia, A. B. R.; STAB, Açúcar, Álcool e Subprodutos, 1994, 12, 29.

15. Azevêdo, L. C.; Reis, M. M.; Silva, L. A.; Andrade, J. B.; Quim. Nova 2007, 30, 1968.

16. Bogusz Junior, S.; Ketzer, D. C. M.; Gubert, R.; Andrades, L.; Gobo, A. B.; Cienc. Tecnol. Aliment. 2006, 26, 793.
17. Pereira, N. E.; Cardoso, M. G.; Azevedo, S. M.; Morais, A. R.; Fernandes, W.; Aguiar, P. M.; Cienc. Agrotec. 2003, 27, 1068.

18. Parazzi, C.; Arthur, C. M.; Lopes, J. J. C.; Borges, M. T. M. R.; Cienc. Tecnol. Aliment. 2008, 28, 193.

19. Boza, Y.; Horii, J.; Cienc. Tecnol. Aliment. 1998, 18, 391.

20. Boza, Y.; Horii, J.; B. CEPPA 2000, 18, 85.

21. Maia, A. B. R. A.; Campelo, E. A. P.; Tecnologia da Cachaça de Alambique, Editora SEBRAE/MG; SINDBEBIDAS: Belo Horizonte, 2006.

22. Miranda, M. B.; Horii, J.; Alcarde, A. R.; Ciênc. Tecnol. Aliment. 2006, 26, 772 .

23. Cardoso, M. G.; Campos, G. A.; Silva, R. A.; Santos, C. D.; Pinto, A. P. S.; Silva, C. F.; PROEX/UFLA. Disponivel em http://www.editora.ufla. br, acessada em Julho 2005.

24. Raven, P. H.; Evert, R. F.; Eichhorn, S. E.; Biologia Vegetal, 6 ${ }^{\text {a }}$ ed., Ed. Guanabara Koogan: Rio de Janeiro, 2001.

25. Nascimento, R. F.; Cardoso, D. R.; Lima Neto, B. S.; Franco, D. W.; Quim. Nova 1998, 21, 737.

26. BRASIL. Ministério da Agricultura, Pecuária e Abastecimento; Portaria $\mathrm{N}^{\circ} 371$, de 18 de setembro de 1974, Diário Oficial da União 19/09/1974.

27. Barcelos, L. V. F.; Cardoso, M. G. C.; Vilela, F. J.; Anjos, J. P.; Quim. Nova 2007, 30, 1009.

28. Yokoya, F.; Fabricação de aguardente de cana, Campinas, 1995.

29. Crowell, E. A.; Am. J. Eco. Viticul. 1961, 12, 111.

30. Nascimento, R. F.; Marques, J. C.; Lima Neto, B. S.; Keukeleire, D. D.; Franco, D. W.; J. Chromatogr. 1997, 782, 13.

31. Oliveira, E. S.; Tese de Doutorado, Universidade Estadual de Campinas, Brasil, 2001. 